\title{
Medullary Cystic Disease and Juvenile Nephronophthisis in Separate Members of the Same Family
}

\author{
M. J. SWORN and A. J. EISINGER \\ From the Departments of Pathology and Medicine, University of Sheffield
}

\begin{abstract}
Sworn, M. J., and Eisinger, A. J. (1972). Archives of Disease in Childhood, 47, 278. Medullary cystic disease and juvenile nephronophthisis in separate members of the same family. The clinical and pathological findings in three sibs dying in renal failure at 9,15 , and 21 years of age respectively are presented. The three sibs showed a similar clinical presentation with an insidious onset of azotaemia without hypertension in association with obligatory dilute urine virtually free of albumin and formed elements. There was renal osteodystrophy in all cases with tertiary hyperparathyroidism in one case.

Necropsies were performed on the boy dying at 9 years of age and the girl dying at 21 years of age. In the former the renal histology most closely corresponded to that described in juvenile nephronophthisis while in the latter the appearances were those of medullary cystic disease.

We hence affirm that familial juvenile nephronophthisis and medullary cystic disease are basically the same disease and suggest that the developement of cysts may be a secondary process, possibly consequent upon interstitial fibrosis and basement membrane thickening, becoming more pronounced with length of survival.

The diagnosis in life may be suggested by the familial incidence and characteristic clinical presentation supported by renal biopsy.
\end{abstract}

Reviewing the subject of congenital cystic kidneys early in this century, Bunting (1906) felt that so numerous and varied were the attempts to explain the pathogenesis of congenital cystic kidneys that he was inclined to question whether pathologists had been dealing throughout with a single pathological process.

The case of a child with intractable anaemia, obligatory hypotonic urine, and progressive azotaemia despite minimal urinary changes in association with multiple cysts localized to the renal medullae was described by Smith and Graham (1945). This enabled the separation of medullary cystic disease from polycystic renal disease in general, diagnostic emphasis being placed on the cystic lesions, perhaps to the neglect of the parenchymal changes.

Fanconi et al. (1951) described two families with a total of 8 children who presented a similar clinical course of nonhypertensive azotaemia of

Received 1 October 1971. insidious onset with obligatory hypotonic urine but no albuminuria at any time. Histologically the kidneys revealed extreme atrophy and fibrosis of both glomeruli and tubules associated with a moderate interstitial cellular infiltration but cyst formation was not described. This nephropathy became known as familial juvenile nephronophthisis.

Subsequent cases of these conditions have been reported including familial cases of medullary cystic disease and recently the similarity between the clinical features and histology of these two conditions noted (Strauss and Sommers, 1967).

In describing 3 sibs with similar clinical presentations, in which one showed histological features of familial juvenile nephronophthisis and another showed changes of uraemic medullary cystic disease, we wish to affirm the unity of these two conditions.

\section{Case Reports}

The parents of the 3 sibs to be described showed no evidence of renal disease. There is no history of 
consanguinity and no other relative is known to have suffered from renal disease. All 3 children of this marriage died in renal failure at 9,15 , and 21 years respectively, following a similar clinical course.

Case 1 (Frederick G.). Born September 1945, the eldest of the 3 sibs; his birth and early development were normal. At the age of 9 he presented with an 18-month history of pains in the legs particularly at night, polydipsia, polyuria, and late onset enuresis. Examination showed a pale dehydrated boy, whose blood pressure was $100 / 70 \mathrm{mmHg}$, with a dilated right pupil and nystagmus in the right eye on medial gaze. The ocular abnormalities had been present all his life. Investigations on admission revealed a blood urea of $225 \mathrm{mg} / 100 \mathrm{ml}$, a serum potassium of $3.0 \mathrm{mEq} / \mathrm{l}$., and a serum sodium of $125 \mathrm{mEq} / \mathrm{l}$. The serum sodium was persistently low whenever measured. Repeated urine examination revealed no abnormality apart from mild albuminuria. Skeletal $x$-rays suggested renal osteodystrophy, the serum calcium was $9.0 \mathrm{mg} / 100 \mathrm{ml}$, and phosphate $4.9 \mathrm{mg} / 100 \mathrm{ml}$. He died 2 weeks after admission with a blood urea of $270 \mathrm{mg} / 100 \mathrm{ml}$.

At necropsy a moderately oedematous brain and abnormal kidneys were the only significant findings. Both kidneys were pale and showed cortical thinning. The pelvicalyceal systems, ureters, and bladder were normal. Microscopically most glomeruli showed contracted tufts with surrounding intracapsular collagen while other tufts were completely sclerosed, of normal size, or enlarged. Occasional pericapsular fibrosis and a few cystic Bowman's capsules were present (Fig. 1). The cortical tubules showed great variation in size and shape, some being dilated and tortuous while others were atrophic. A few tubules had a hyperplastic or immature appearance. The medullae contained a few cysts which varied from $0.2 \mathrm{~mm}$ to $3 \mathrm{~mm}$ in diameter lined by flattened or cuboidal epithelium, between which tortuous loops of Henle and collecting ducts were

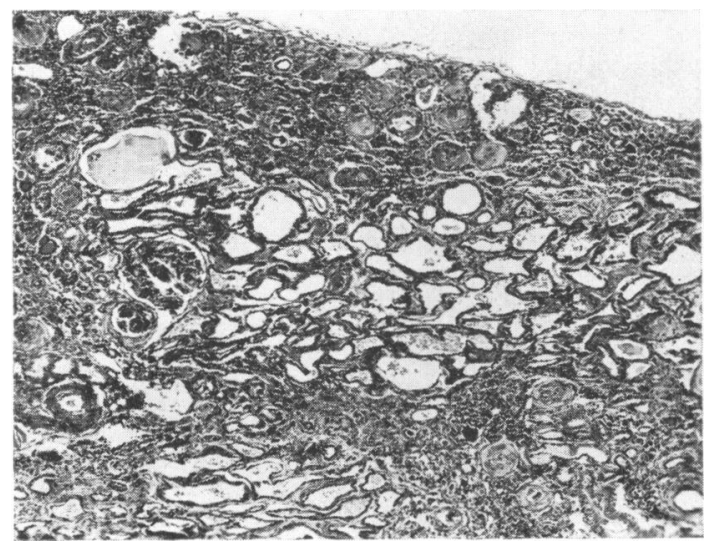

Fig. 1.-Renal cortex of Case 1 showing hyalinized glomeruli and atrophic and irregularly dilated tubules. (Masson trichrome $\times 34$.) apparent. Many of the collecting ducts were lined by a dense hyperplastic or immature epithelium (Fig. 2). There was a diffuse interstitial fibrosis which was extremely dense and cellular in the medullae and a diffuse interstitial inflammatory infiltrate composed predominantly of lymphocytes. The vessels were unremarkable.

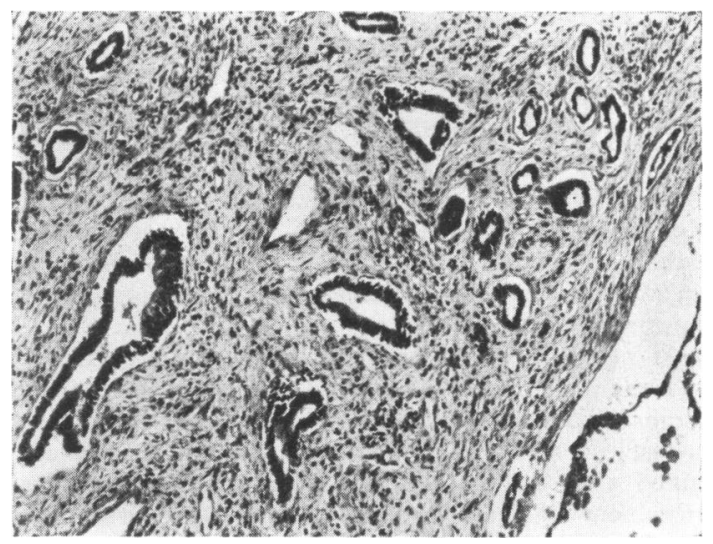

FIG. 2.-Renal medulla of Case 1 showing dense interstitial fibrosis between collecting ducts which possess a hyperchromatic hyperplastic or immature type of epithelium. Part of a cyst with detached epithelium is also present. (Haematoxylin and eosin $\times 68$.)

Case 2 (John G.). Born November 1946, 14 months after his brother; his birth and early development were normal. At age 6 he was noted to have poor vision and found to have a mixed astigmatism. He was investigated when aged 10 because of late onset enuresis, polydipsia, and polyuria of 2 months duration. Apart from his ocular abnormalities previously noted, clinical examination was negative. Investigation revealed a raised blood urea $(50-80 \mathrm{mg} / 100 \mathrm{ml}), \mathrm{Hb} 12.6$ $\mathrm{g} / 100 \mathrm{ml}$, and an intravenous pyelogram showed poor concentrating ability, but the urine was free of albumin and contained no casts or deposits. Skeletal $x$-rays suggested renal rickets. Renal failure and rickets progressed accompanied by increasing anaemia. Exploratory surgery was performed on his neck when aged 15 for possible parathyroid enlargement but the glands were found to be of normal size. He died at home later the same year.

Case 3 (Dorothy G.). Born October 1948, the third child; her birth and early development were normal. She was first investigated at the age of 8 because of renal disease in both her brothers. An intravenous pyelogram and blood urea at that time were normal and the urine was reported as showing mild proteinuria and some hyaline casts. She presented clinically when aged 20 with anaemia, polyuria, and polydipsia. Her blood pressure was $130 / 70 \mathrm{mmHg}$. Investigation revealed a blood urea of $190 \mathrm{mg} / 100 \mathrm{ml}$, 
Hb $8 \cdot 75 \mathrm{~g} / 100 \mathrm{ml}$, and entirely normal urine. Renal biopsy was performed and she received dietary treatment and subsequently intermittent peritoneal dialysis. 20 months after her clinical presentation she was admitted to hospital with vomiting, aching in the legs, retrosternal pain, cough, and diarrhoea. Investigations at this time revealed a blood urea of $324 \mathrm{mg} / 100 \mathrm{ml}$, a serum calcium of $11.2 \mathrm{mg} / 100 \mathrm{ml}$, a serum inorganic phosphorus concentration of $18.0 \mathrm{mg} / 100 \mathrm{ml}$, and a haemoglobin of $7 \cdot 2 \mathrm{~g} / 100 \mathrm{ml}$. Shortly after admission she suddenly died.

The renal biopsy performed 10 months before death contained about a dozen glomeruli of which 9 showed complete sclerosis with hyalinization, one showed intracapsular, and one pericapsular fibrosis; one glomerulus appeared normal. The tubules showed extensive atrophy with interstitial fibrosis which was accompanied by an infiltration of lymphocytes and a few plasma cells.

At necropsy all 4 parathyroid glands were enlarged and one contained a discrete adenoma with an adjacent compressed rim. The lungs were oedematous, showed metastatic calcification, and the pleural cavities contained straw-coloured effusions. The vertebrae showed prominent lacunar resorption and osteitis fibrosa. The left kidney weighed $75 \mathrm{~g}$ and the right $100 \mathrm{~g}$, with thinning of their cortices and lobulated but otherwise smooth subcapsular surfaces. Their medullae contained multiple cysts which varied in size from approximately $0 \cdot 2-2 \cdot 0 \mathrm{~cm}$ in diameter (Fig. 3) and contained clear fluid. The pelvicalyceal systems appeared normal. Microscopically the external $1 \mathrm{~mm}$ of the renal cortices contained many cystic Bowman's capsules. Glomeruli appeared reduced in number and those surviving showed a variety of changes. Many showed periglomerular fibrosis but appeared of normal size while others were hyalinized. Occasionally adhesions were present between glomerular tufts and Bowman's capsules. The tubules were tortuous and showed moderate variation $\stackrel{\rho}{\supset}$ in size. Their epithelial linings were on the whole of low cuboidal type with prominent basement membrane $\Rightarrow$ thickening in some areas. Occasional tubules were lined by a hyperplastic or immature type epithelium. Multiple large cysts lined by single-layered flattened or cuboidal $\bar{\sigma}$ epithelium were present in the medullae while the $\overline{\bar{C}}$ adjacent collecting ducts were tortuous and showed variable basement membrane thickening. There was a dense interstitial fibrosis, a lymphocytic infiltrate in $\omega$ cortex and medulla, and a few scattered calcific deposits. $\vec{\circ}$ The arteries showed moderate intimal and fibromuscular thickening.

\section{Discussion}

Though histological proof was lacking in one case, the clinical similarity suggests that all 3 sibs in suffered from uraemic medullary cystic disease or $N$ juvenile nephronophthisis. In recent years it has been suggested that uraemic medullary cystic disease and juvenile nephronophthisis are the same disease (Strauss and Sommers, 1967). It is understandable that the unity of these two conditions was not recognized, since juvenile nephronophthisis was described as a familial disease occurring in a younger age group than medullary cystic disease, while cystic change, an obvious feature of the sporadic medullary cystic disease, was not reported to be a prominent feature of juvenile nephronophthisis (Fanconi et al., 1951; Strauss, 1962). It is pertinent that in Frederick G. (Case 1 ), who died aged 9 years, the renal pathology would have been classified as juvenile nephronophthisis whereas in Dorothy G. (Case 3), who died at 21 years of age, the kidneys showed the changes of

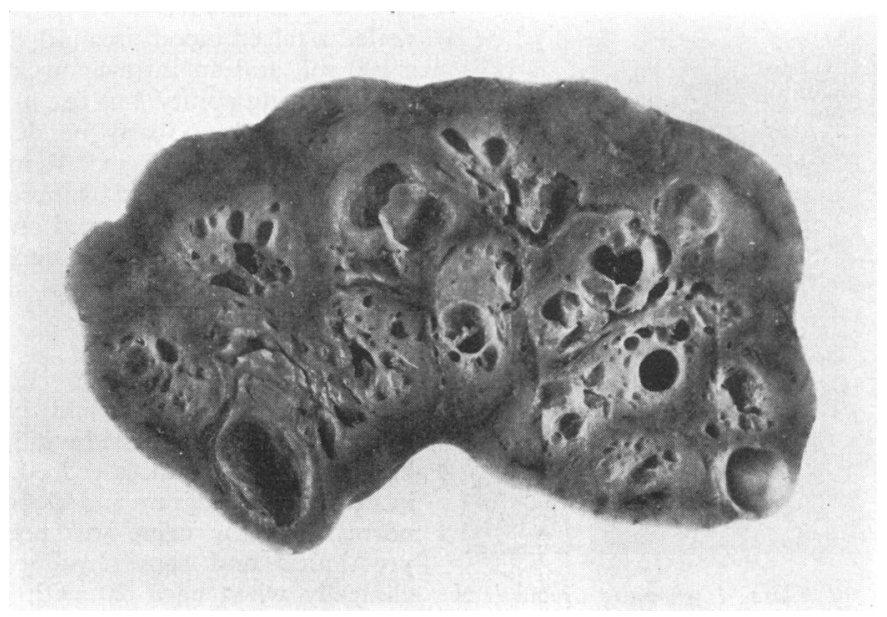

Fig. 3.-Slice of one kidney from Case 3 showing multiple medullary cysts and a cortical cyst. 
medullary cystic disease. This suggests that the development of the cysts may be a secondary process, the lesions becoming more pronounced with length of survival.

The hereditary basis of medullary cystic disease has now been amply confirmed. Several families have been reported in which the condition was seen in both vertical and lateral relationships (Goldman et al., 1966; Herdman, Good, and Vernier, 1967; Mongeau and Worthen, 1967). There was no consanguinity of the parents of our cases and no evidence of disease in any close relative but all the children were affected, there being no remaining normal sibs. There may well be an associated genetic defect between various ocular abnormalities and the renal condition in view of the findings in these sibs and previous case reports (Fairley, Leighton, and Kincaid-Smith, 1963; Herdman et al., 1967; Senior, Friedmann, and Braudo, 1961).

The basic renal defect is probably tubular with secondary glomerular damage (Hooft, Roels, and Herpol, 1959). This explains the normal urinary deposit and the paucity of albuminuria both characteristic of the disease. The resulting disruption of the countercurrent renal concentrating mechanism explains the early polyuria and inability to produce hypertonic urine (Strauss, 1962).

The diagnosis in these 3 cases was made at necropsy on the death of the third case. In retrospect it might have been tentatively diagnosed because of certain suggestive clinico-pathological features. Firstly the familial incidence, secondly the presence of virtually normal urine in conjunction with severe chronic renal disease, and thirdly in the first case at least a tendency to renal sodium loss. Ocular abnormalities found in 2 of these cases were possibly also a suggestive feature.

We are indebted to Dr. Margaret M. Platts for use of her clinical records, to Dr. A. J. N. Warrack for the necropsy report and renal blocks of Case 1 , and to Professor W. A. J. Crane and Dr. J. L. Emery for helpful advice and criticism.

\section{REFERENCES}

Bunting, C. H. (1906). Congenital cystic kidney and liver with family tendency. Fournal of Experimental Medicine, 8, 271.

Fairley, K. F., Leighton, P. W., and Kincaid-Smith, P. (1963). Familial visual defects associated with polycystic kidney and medullary sponge kidney. British Medical fournal, 1, 1060.

Fanconi, G., Hanart, E., Albertini, A. V., Ühlinger, E., Dolivo, G., and Prader, A. (1951). Die familiäre juvenile Nephronophthise (die idiopathische parenchymatöse Schrumpfniere). Helvetica Paediatrica Acta, 6, 1.

Goldman, S. H., Walker, S. R., Merigan, T. C., Jr., Gardner, K. D., Jr., and Bull, J. M. C. (1966). Hereditary occurrence of cystic disease of the renal medulla. New England fournal of Medicine, 274, 984

Herdman, R. C., Good, R. A., and Vernier, R. L. (1967). Medullary cystic disease in two siblings. American fournal of Medicine, 43, 335.

Hooft, C., Roels, H., and Herpol, J. (1959). A case of Fanconi's familial juvenile nephronophthisis. Helvetica Paediatrica Acta, 14, 217.

Mongeau, J. G., and Worthen, H. G. (1967). Nephronophthisis and medullary cystic disease. American fournal of Medicine, 43, 345.

Senior, B., Friedmann, A. I., and Braudo, J. L. (1961). Juvenile familial nephropathy with tapetoretinal degeneration. American fournal of Ophthalmology, 52, 625.

Smith, C. H., and Graham, J. B. (1945). Congenital medullary cysts of the kidneys with severe refractory anemia. American fournal of Diseases of Children, 69, 369.

Strauss, M. B. (1962). Clinical and pathological aspects of cystic disease of the renal medulla. Annals of Internal Medicine, 57, 373.

Strauss, M. B., and Sommers, S. C. (1967). Medullary cystic disease and familial juvenile nephronophthisis. New England fournal of Medicine, 277, 863.

Correspondence to Dr. M. J. Sworn, Department of Pathology, The University, Western Bank, Sheffield S10 2TN. 